\title{
Application of Policy Deployment and Daily Management in service sector
}

\author{
Anil Sachdev *i] and Jitendra Agrawal
}

* Correspondence: anil@tami.com TQM International Pvt. Ltd., New Delhi, Delhi, India

\begin{abstract}
Background: Policy Deployment and Daily Management are two critical vehicles of Total Quality Management implementation in a company. Integration of these two vehicles has been discussed and adequately addressed in a few companies that have been practicing Total Quality Management for a long time. However, most companies often face challenges and difficulties in ensuring smooth and seamless transfer of Policy Deployment plans into Daily Management activities.

Case description: The challenge is even bigger in service sector which embarked on the Total Quality Management journey barely 5-6 years ago. The service sector has traditionally used Balanced Scorecard which has relatively weaker emphasis on the means to achieve the targets. The authors of this report have found a customized and unique model whose success has been demonstrated through deployment in two customer-facing processes in a large life insurance company in India. The traditional approach used in manufacturing industry has been simplified and customized for the effective application in the service sector.
\end{abstract}

Discussions \& Evaluation: The traditional approach used in manufacturing industry has been simplified and customised for the effective application in the service sector. A survey was done to identify the issues and the approach was modified and implemented in couple of key customer-facing processes.

Conclusion: The phenomenal results have led to a big 'pull' from other process owners to replicate this approach across all operational and support processes. Initial 'reluctant participants' of the process have now become the 'champions' and truly the 'change catalysts' for this approach. The process is now being replicated in several other processes across several Industrial sectors.

Keywords: TQM, Policy Deployment, Daily Management, QI Story (Quality Improvement Projects), BPM (Business Process Management)

\section{Background}

All companies are facing business challenges and are working towards business enhancement through structured processes like TQM/Lean/Six Sigma. In order to become leaders in a highly competitive business, each company is trying to outdo the others. The use of traditional Japanese way of TQM in the service sector has been limited. A few companies are now attempting it in the face of stiff competition.

As per JUSE (Union of Japanese Scientists and Engineers) Deming Prize Guideline [1], Total Quality Management is defined as 'a set of systematic activities carried out by the entire organization to effectively and efficiently achieve company objectives so

(c) The Author(s). 2017 Open Access This article is distributed under the terms of the Creative Commons Attribution 4.0 International License (http://creativecommons.org/licenses/by/4.0/), which permits unrestricted use, distribution, and reproduction in any medium, provided you give appropriate credit to the original author(s) and the source, provide a link to the Creative Commons license, and indicate if changes were made. 
as to provide products and services with a level of quality that satisfies customers, at the appropriate time and price.' The companies aspiring to implement TQM need to address three aspects:

i. The company prepares customer facing and challenging business objectives and strategy in line with business environment

ii. The company implements TQM to achieve business objectives and strategy

iii. The business results/effects are an outcome of the point (ii) above

TQM uses two vehicles for focused strategic improvements and sustenance-Policy Management and Daily Management. Kume [2] defines Policy Management as 'a management technique for developing the issues required for implementing the business plan and implementing the PDCA cycle (i.e. making plans, implementing them, checking the results and taking corrective actions) in line with the vertical structure of an organisation'. Goals and means of Managing Director need to be deployed vertically down the line to respective managers and section heads.

\section{Policy Management}

Policy Management has two components:

1. Formulate the policy (consisting of themes of business improvement, target and prioritisation of means)

2. Deploy the policy (both the themes and means) for effective execution

Both the formulation and execution is critical for effective business results, as can be seen by Fig. 1. Neither of them alone is sufficient for delivering the desired effects. For a policy item to be implemented through organisational activities, it must be developed hierarchically or broken down to suit the structure of the existing organisation. The tasks that must be accomplished to achieve the objectives must be clarified, and the role of each division must be allocated in such a way that the organisation as a whole can move towards attaining those objectives. Policy Management is a method of achieving this.

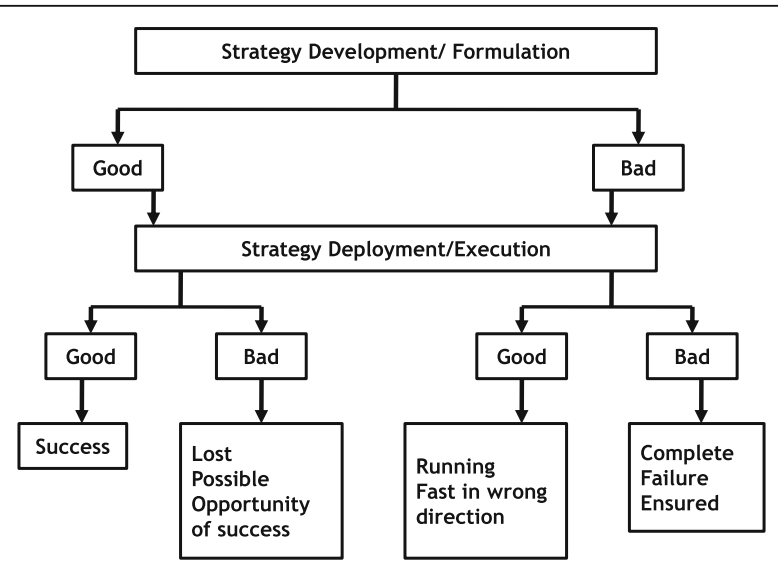

Fig. 1 Importance of strategy formulation and execution 
Policy Management gives a fairly balanced approach for both formulation and execution. It aligns the company's annual business plan to mid-term and longterm strategy of the company. Due to effective deployment process throughout the organisation, this approach also helps align department, section and individual goals to the company's annual business plan. Policy Management has been used in several manufacturing companies in India, especially those who have won or are working for Deming Prize/TPM (Total Productive Maintenance) Award/ TPS (Toyota Production System). Policy Management has also been used in many companies outside India like Komatsu, Toyota, Honda and Hewlett-Packard.

However, most service organisations have been using Balanced Scorecard (BSC). Balanced Scorecard concept, with a set of measures that gives top managers a fast and comprehensive view of the business, was devised by Kaplan and Norton [3] after 1 year of research in 12 companies. It defines company performance, measured from four different perspectives: Customer and Market, Financial, Internal Processes and Learning and Growth, in a fairly balanced way. The idea was to avoid too much focus on financial/short-term profits. These four perspectives are well inter-connected. Financial goals can be achieved if customers are satisfied, which is possible with better internal processes, which in turn is possible if employees learn and grow.

Noteworthy aspects of Policy Management compared to Balanced Scorecard as per Hosotani [4] include the following:

- Major (priority) points are clarified as business target, and the means to achieve them are assured for effective action taking.

- QC-like problem solutions are used for the major points.

- The President's policies are deployed to department heads for a more organic, top-to-bottom tie-in.

The means identified for achievement of business targets take the shape of simple themes for execution (or just-do-it) where the solution is obvious. Else they use of QC/QI problem solving methods where the root cause and/or solutions are not so evident. Kume [5] gives a simple yet effective seven-step process for problem solving QC/QI story that have evolved out of Deming's famous PDCA (plan-do-check-act) cycle. The seven steps are:

- Define (reason for improvement with clear problem and goal statement)

- Observation (understand current situation from different perspectives)

- Analysis (identify and validate root cause)

- Action (create countermeasures)

- Check (results/effects)

- Standardise (introduce process and practice to hold the gains)

- Conclusion (reflection and future plan)

\section{Daily Management}

Once solutions are implemented, they are sustained with effective Daily Management. Ando and Kumar [6] define Daily Management as 'all those routine activities that must 
be carried out efficiently. While maintenance activities are the main concerns, improvement activities are also part of daily management'.

While Daily Management was initially used by Kansai Electric, Komatsu and others, it is now regarded as the basic foundation for TQM implementation. Learning with application of Daily Management has led to the publication of Japanese Industrial Standard JIS-Q-9026 [7] on the subject. Daily Management is a matter of concern in most organisations due to excessive focus on daily fires and lesser attention towards the next level of improvement.

According to Hosotani [4], Daily Management encompasses those activities that achieve the work target efficiently in regard to the department's job. This is the most basic activity for divisional/departmental control. On the other hand, Policy Management is an activity to achieve management policies based on the organisational priorities.

As per Ando and Pankaj [6], all the issues relating to policy are very important to the organisation, but Daily Management issues are no less important. In terms of significances and consequences, both Daily Management and Policy Management are equally important. To the Senior Management, Policy Management could matter much more than Daily Management, as they should deal more with strategic issues. To devote their time to Policy Management, they should standardise the activities and empower their people to perform Daily Management. On the other hand, the frontline employees have a good deal of time to spend on Daily Management activities. However, to realise the company's vision and objectives, the frontline employees also have a role in dealing with strategic issues, thus contributing to Policy Management activities.

So, in short, priority improvement themes are selected from the annual policy of the company, QC/QI Story is used to execute the themes and Daily Management is used to sustain the improvement over time. These three approaches are strongly linked and complement each other to get the desired business results.

Policy Management essentially uses PDCA cycle while Daily Management uses SDCA (standardise-do-check-act). While the PDCA of Policy Management questions the status quo and enables to find a better way, SDCA cycle of Daily Management helps maintain the status quo and ensures stability of the process.

Large number of manufacturing companies in India and overseas has used these two cycles successfully in their operations. However, their application has been limited in the service sector, for which there could be two reasons. One is that the language and terminology relate better with manufacturing sector. Another is that the nature of the business complexity and people mind set in service sector are different.

\section{Case Description}

\section{Application in service sector}

Kano [8] study on why few service sector companies have started using TQM showed the following as prime reasons:

- Intensified competition

- Looking at the future of the company

- Facing critical problems 
- New President/Leadership team

- Influence from other companies

- TQM does match the business philosophy, belief and direction of top management

Sachdev [9] highlighted the challenges in service sector:

- Processes and outputs are often invisible

- Errors are known only when used by the customer

- Process changes are individual initiated

- Lack of proper measure for performance tracking

- Lack of data and facts

- Late starters in improvement journey (compared to manufacturing sector)

- High rate of employee attrition

- Greater emphasis on 'fixing' the problem and not on recurrence prevention

Similar challenges were observed when the authors tried to implement TQM in a large life insurance company in India. In addition, the life insurance business in India is highly regulated. It was opened to the private sector only 16 years ago and has too many players. The intensely competitive and highly regulated environment led to challenges on sales and business growth for all private insurance players. Some unfair/ unethical practices also emerged (such as mis-selling) with false promises made to customer at the time of new business acquisition. As a result, customer complaints increased, leading to even higher intervention by the regulator.

Some applications of Six Sigma/Lean and also some individual suggestions were used to address these concerns. Hence, Agrawal [10] advocated TQM as an integrated approach for the service sector, specifically for the insurance industry which is at a nascent stage of implementing continuous improvement using the principles of Total Employee Involvement (TEI) and Total Waste Elimination (TWE).

Experience shows that while most organisations have a noble intent to drive a culture of value addition and customer centricity and achieve tangible results, however, they are often lost in their excitement of implementing improvement program, missing the essence of 'discipline, 'integration' (of these interventions) and linkage to 'customer and financial' results. TQM is a holistic approach that binds the organisation to business excellence by emphasising customer orientation, setting and achieving challenging objectives, driving first time right transactions across the touch points, training and cross-training people, empowering employees, using appropriate data and statistical analysis (for decision making and problem solving for continuous improvement) and focusing on quick win as well as long-term practices and business results.

Understanding the common scepticism about application of traditional TQM methods such as Policy Management and Daily Management in service environment, the authors balanced the approach by blending the power of TQM principles, process and tools with effective facilitation. They aimed to make the team achieve challenging objectives and enhance its confidence by piloting the TQM process on selected customer facing processes. Hence, the concepts, methods and tools used in this case were fairly simplified to achieve a higher acceptability and thereby better chance of success. Learning from several applications in manufacturing sector have been made 
use for customising and evolving a more suitable, simpler and easy to understand approach that is highly effective.

\section{Assessing current status in Indian service industry}

A quick survey was conducted covering 26 senior executives of companies working on TQM or equivalent methodology for business excellence. Survey questionnaire used is shown as Additional file 1. The sectors covered during the survey included Insurance, Banking, Retail and IT and IT enabled service. The survey primarily focused on current status and future plan on Policy Management (or equivalent). The companies selected for the survey have been working on the process for at least 5 years. Some key findings of the survey include the following:

- Sixty-two percent of companies follow Balanced Scorecard, and the remaining $38 \%$ use strategic planning. No company in the survey sample was using the traditional Japanese method of Policy Management/Hoshin Kanri.

- All respondents indicated that major failure is on strategy execution. Strategy formulation process is generally perceived to be good.

- One concern expressed by most respondents is lack of prioritisation. Thirty percent of respondents had indicated five to eight priority areas, and 50\% work on more than eight areas for annual business planning cycle.

- Most responses (> 85\%) indicated that it took more than 2 years to get some maturity in Business Planning Cycle/Balanced Scorecard process. The rest felt that they are still struggling to stabilise and reach a fair level of maturity even after 45 years of practice.

- Top five challenges in Policy Management/Balanced Scorecard (PM/BSC) that emerged in the survey are as follows:

- More focus on business results and much less focus on the processes

- Lack of prioritisation

- Lack of understanding the process of PM/BSC

- Role clarity in deployment of Leadership Policies to the operational level

- Lack of effective deployment to operational level for execution

- Major actions taken by the companies for addressing these challenges are as follows:

- Training across the organisation

- Mentoring by leadership team

- Revisited the review mechanism

- Used only three to five focused items of high priority for the year

- Actions to sustain the performance due to less focus on standardisation and routine/Daily Management

- Activities being planned for further improvement and strengthening PM/BSC process by the companies surveyed:

- HR drive for training and linking PM/BSC goals for Individual Performance Management System

- Drive improvement projects and initiatives linked to bigger organisational goals

- Work out easy to manage and understand system, as applicable for frontline teams

- Create project rigour for execution of taking planned initiatives 
- Bring clarity on KRA (key result area) vs. KPI (key performance indicator)

- Support teams to identify focussed, sharper and quantitative KPIs

- Compare the performance w.r.t. competition and the benchmarks

- Strengthen review process among the operating team, functional head and the senior management

- Tracking and escalation of gaps for time-based closure

- Prioritise not more than three to five big goals and drive initiatives across relevant functions and cross functional teams

- Strengthen standardisation and Business Process Management (BPM) activities

The learning from various Gurus, application in several organisations in the manufacturing sector and findings of the above survey helped us define a simpler yet effective approach for the service sector. The approach was used in a large life insurance company in India. Needless to say, the approach had to undergo many refinements as we kept learning during application. The case below shows an approach as applied and effects thereof.

\section{Application of Policy and Daily Management in a life insurance company}

HDFC Life is a leading private life insurance company catering 64 million customers spread across 940 locations in India and Dubai. It employs 15,000 professionals to support these customers through its network of 414 branches and spokelocations. HDFC Life's product portfolio comprises of solutions, which meet various customer needs such as protection, pension, savings, investment and health coverage. It offers different group products for the varying needs of employers ranging from term insurance plans offering pure protection to voluntary plans such as superannuation and leave encashment.

Insurance is a highly process centric industry where the 'trust' of people plays a key role both internally and externally. The competition is intense; on one side, the smaller players are trying to get their house in order and at the same time, the game is not easy for those on the top to retain their leadership position. Winning customers for a long time and giving them a delightful customer experience is the mantra today.

Requirements of various forms, customer information and documentary proofs are considerably more in insurance business in comparison with banking and other financial instruments. The distinction here is that though the business is financial, it is associated with the life/death of an individual! Being a financial transaction, compliance and due diligence to financial regulations entail plenty of details, document gathering and form filling. This adds to the complexity and creates situations of customer dissatisfaction and complaint, which demands action within stipulated time. A snap shot of pending complaints as reported quarterly to the regulator is shown in Fig. 2. Trend of customer complaints of HDFC Life is compared with four major competitors (A, B, C and D).

In a pursuit of becoming a world-class organisation, HDFC Life decided to launch the TQM/Deming Journey formally in 2012. A world-class organisation is one which is considered a benchmark within its industry sector and for some aspects, by other sectors as well. HDFC Life recognised that continuous learning, developing capabilities and leading from the front is the way to respond to 


\begin{tabular}{|l|c|c|c|c|c|c|c|c|c|c|}
\hline & \multicolumn{9}{|c|}{ Financial Year 2014-2015 } & \multicolumn{5}{|l|}{ Financial Year 2013-2014 } & \\
\hline Pending complaints & Q1 & Q2 & Q3 & Q4 & Total & Q1 & Q2 & Q3 & Q4 & Total \\
\hline Competitor A & 452 & 272 & 216 & 0 & 940 & 685 & 650 & 315 & 0 & 1650 \\
\hline Competitor B & 559 & 442 & 287 & 0 & 1,288 & 1,456 & 934 & 866 & 432 & 3,688 \\
\hline Competitor C & 111 & 116 & 85 & 111 & 362 & 606 & 500 & 264 & 60 & 1430 \\
\hline HDFC Life & 605 & 345 & 164 & 42 & 1,156 & 1,671 & 1,744 & 1,533 & 48 & 4.996 \\
\hline Competitor D & 96 & 61 & 39 & 36 & 232 & 101 & 112 & 59 & 31 & 303 \\
\hline
\end{tabular}

Fig. 2 Complaint trend and competition comparison

challenging industry requirements. Hence, to achieve better business performance with visible commitment of leadership team, an initiative to become a world-class organisation has been taken to create a culture of customer centric excellence. In this endeavour, a TQM diagnosis was carried by TQM International Pvt. Ltd., a prominent quality management consultancy organisation in India. As a follow-up of the diagnosis, HDFC Life initiated several activities to have better involvement of employees in improvement approaches including 5S, Kaizen and Lean Six Sigma.

To take the initiative to the next level, key areas of the diagnostic report were picked up in the annual policy for FY 2014-15. The MD \& CEO had a vision to reinforce a customer centric policy within the organisation. This involved deploying the policy into specific improvement projects, using QI Story for completion of the projects and integrating revised process with Daily Management/BPM (Business Process Management) System of the company.

HDFC Life has won several awards in reputed forum such as IMC RBNQA, Quality Council of India, Frost \& Sullivan, Banking Frontiers' Finnoviti, QIMPRO Conclave, World Quality Congress, ISQ and NIQR for Quality Improvement Projects and initiatives and also presented papers in prestigious international forums viz. ANQ, JUSE, IAQ and ASQ.

\section{Approach taken}

In insurance, while every interaction with the customer across various touch points is an opportunity to create perceived value, the customer forms an opinion about the organisation during situations when they need the insurance company the most. Among the transactions, two most important moments of truth for customers are (i) when customer is not happy with our products/services and (ii) at the stage of existing relationship, especially when they expect to receive the claim benefits. Hence, the organisation selected these two moment of truth areas for Policy Deployment (PD) projects:

PD 1: Customer payout process (timely and accurate payment against insurance claims)

PD 2: Customer complaint handling process (service recovery) 
The underlining processes in these policies had its own cycle of improvement journey in the past. However, the management felt the need for an end-to-end holistic view. The team drilled down the policy to the key projects for improvement with challenging/stretch targets. One such PD project in QI format for Payout Process is detailed in this paper.

In insurance, there are two categories of payouts namely 'customer-initiated payout' and 'company-initiated payout'. Under each category, there are various sub-categories. Various customer-initiated payouts include Free Look-in, Surrender and Death Claim. Customer-initiated payout includes Maturity and Money Back. The HDFC Life team selected Maturity and Money Back payouts as a first priority for the improvement project (see Fig. 3).

To further prioritise the projects, inter-relationship diagram was used since all these projects were closely inter-linked to each other (refer to Fig. 4). As can be seen, among six projects (PD 1.1.1 to PD 1.1.6), contactability with the customers is critical for the entire policy. This helped the team to focus on right projects and sequence their effort in deployment of the policy.

For each of these projects, a cross-functional team was formed and a governance structure was put into place. They were given a 1-day session on company's vision of becoming a world-class organisation (WCO), key vehicles viz. PD (Policy Deployment) and DM (Daily Management), QI story and simple QC tools. Inter-dependencies among the functions for each of the projects were mapped as a part of stakeholder management process, and relevant resources were made part of the core project and support team (details as per Fig. 5). Policy Deployment projects were positioned quite differently, and that was

Payout is the most important 'Moment of Truth' in the life stages of customer expectations and experience

\section{INSURANCE VALUE CHAIN}

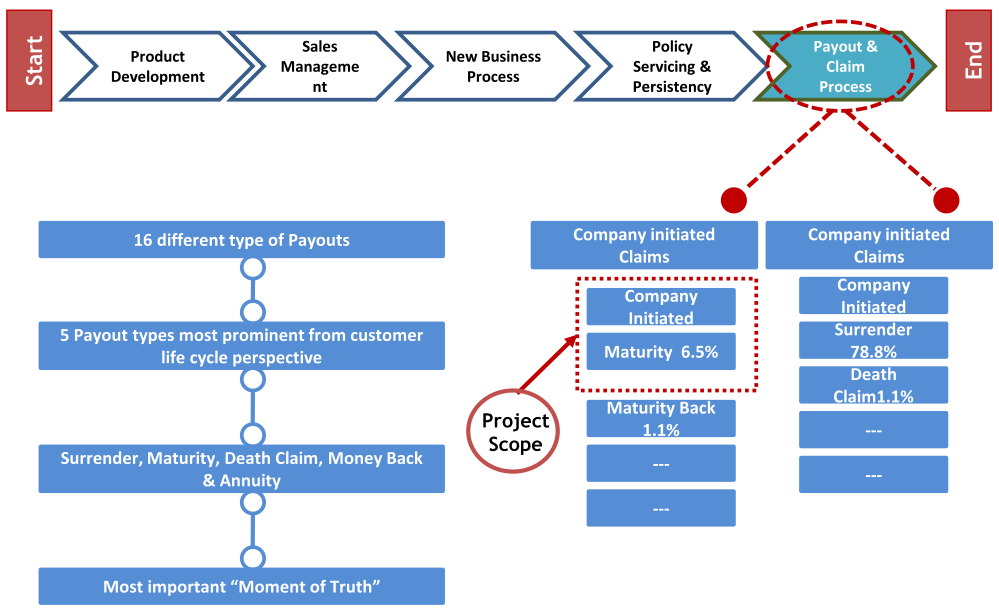

Data source: Life Asia (Insurance Legacy system), Period: Apr-Sept 2014

Fig. 3 Policy Deployment for customer payout process 


\section{Policy Development Opportunity: Lead metrics with baseline} performance

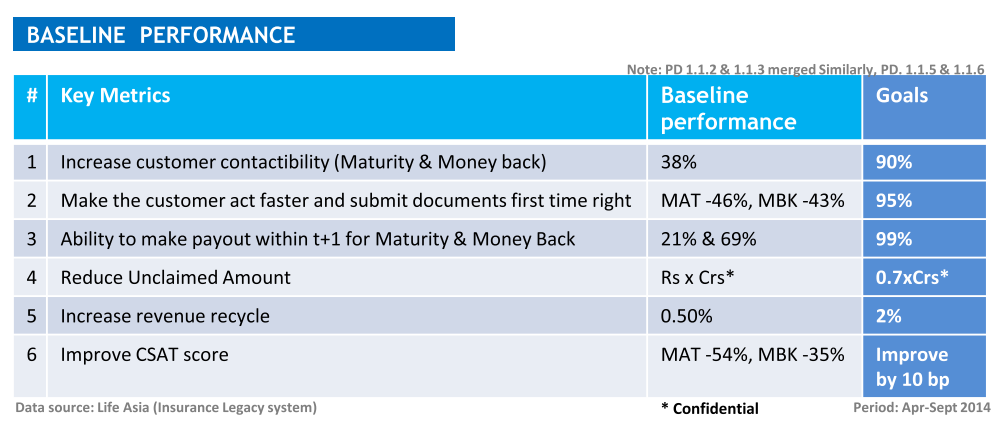

\section{INTER-RELATIONSHIP DIAGRAM}

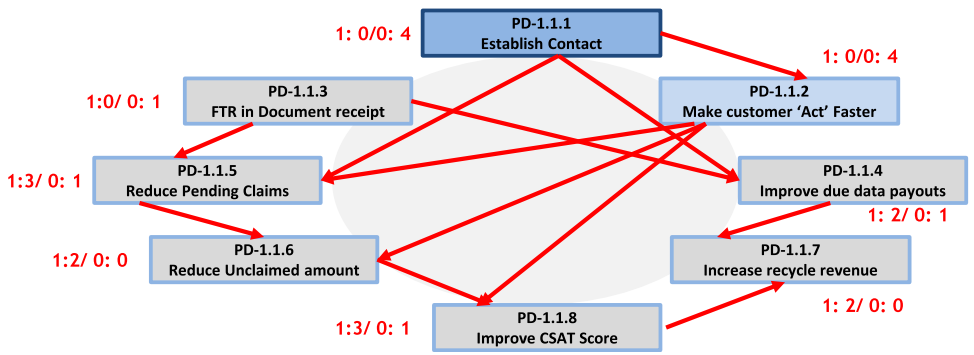

Fig. 4 Prioritisation of projects with relationship diagram

reflecting in the target setting process. Teams were asked to take stretched goals for each of the project, as shown in Fig. 4.

In order to accelerate the project timeline and bring cross-functional team focus on the project, Blitz format was used. This was conducted off-site. The session was facilitated by TQMI team of three consultants and key members of Business \& Service Excellence (BSE) function of the company. The Blitz is comprised of the following:

Project sponsorship from EC \& stakeholder's enrolment for successful project management suitable to organization culture

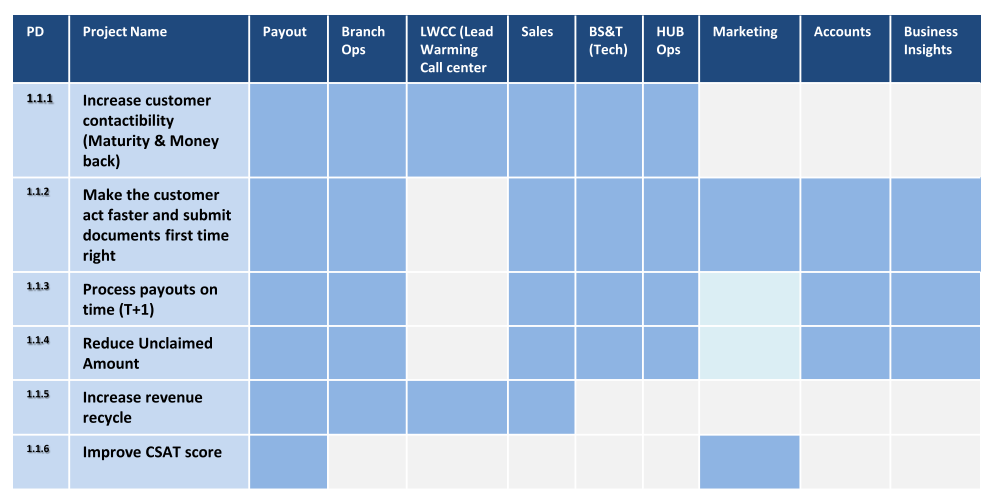

Fig. 5 Cross-functional project linkage 
1. Basic refresher on WCO/TQM diagnosis

2. Training on QI Story, QC tools, simple tools of Lean, RCA, concepts of PDCA vs SDCA cycle

3. Mapping 'as-is' process

4. Finding gaps

5. Mapping 'to be' process

6. Transition plan to move from as-is to to-be

7. Activity breaks down with responsibility, timeframe and sustenance plan.

There were intense discussions among the team members, including on-site and offsite follow-ups. The team gathered relevant qualitative and quantitative data and analysed them before proposing countermeasures. Scenarios were created, and implementation plans were made. Every fortnight, team review/coaching sessions were done by TQMI and BSE to fast track the progress and course correct the actions.

Actions were implemented as per plan; however, there were delays due to work pressure, particularly during the end of the financial year. Further, there were regular reviews by Executive Committee (EC) chaired by the MD \& CEO. The support of EC, particularly MD \& CEO and Heads of Operations and Human Resources, were leading critical success factor. A snapshot of the process changes, countermeasures and results are highlighted in Figs. 6, 7, 8 and 9.

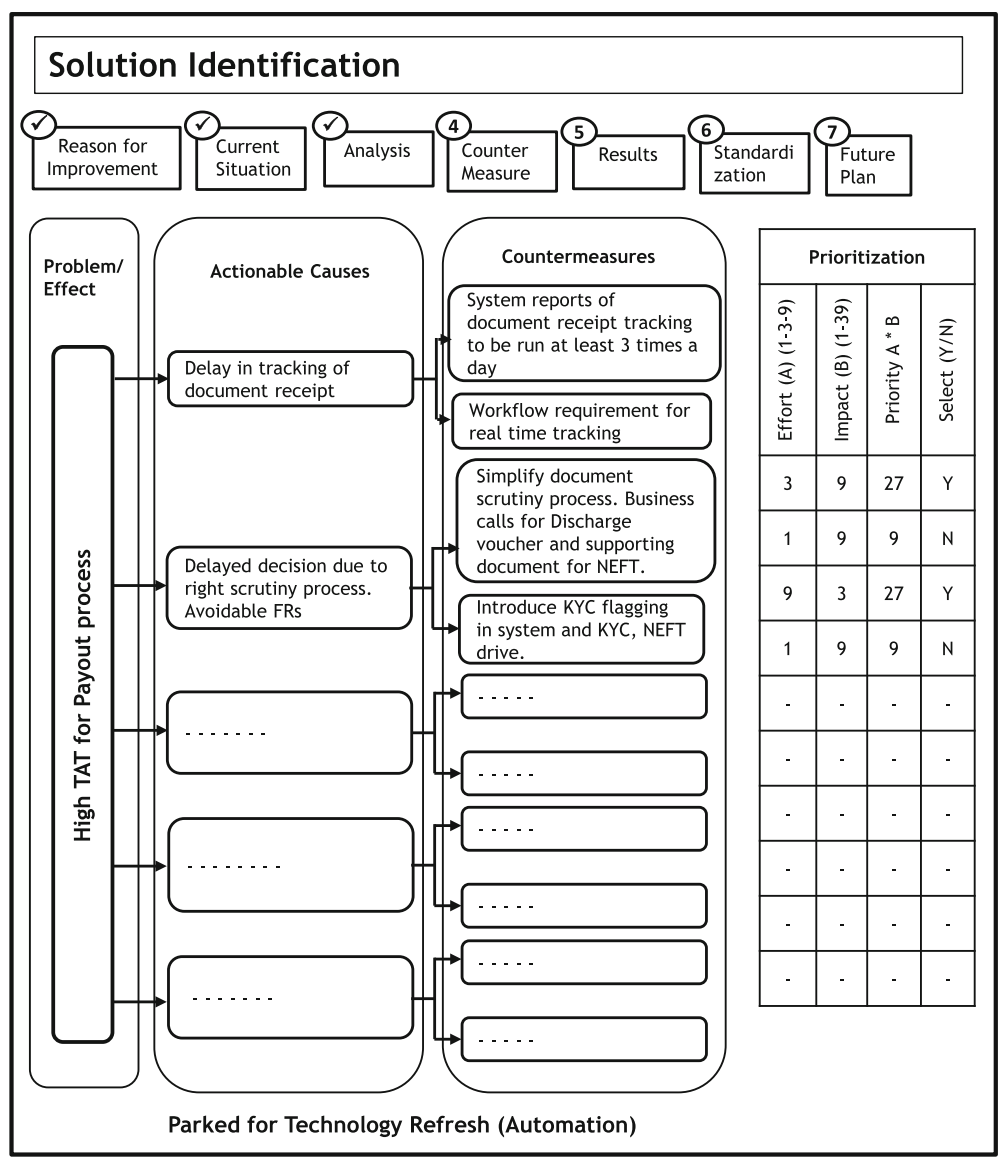

Fig. 6 Use of tree diagram and prioritisation matrix for solution implementation 


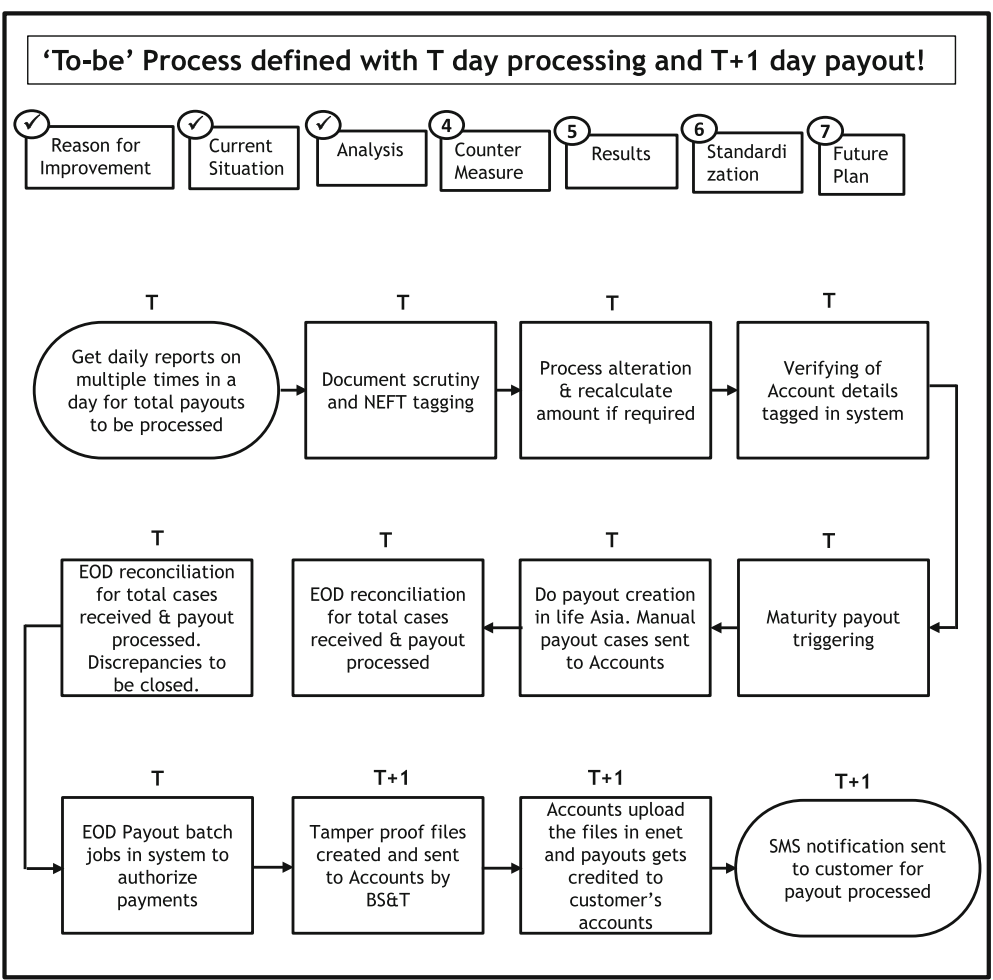

Fig. 7 Revised 'to-be' process map

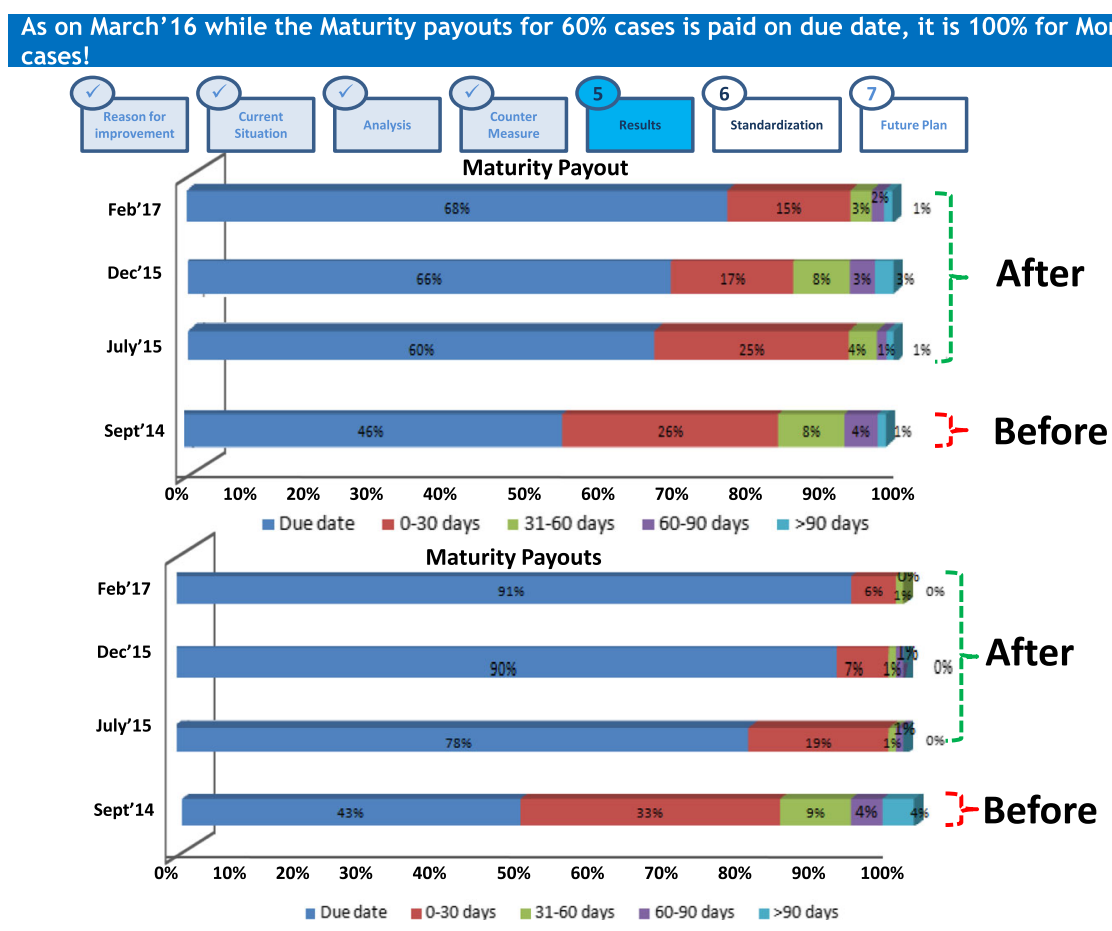

Fig. 8 Process comparison 'before' and 'after' improvement 


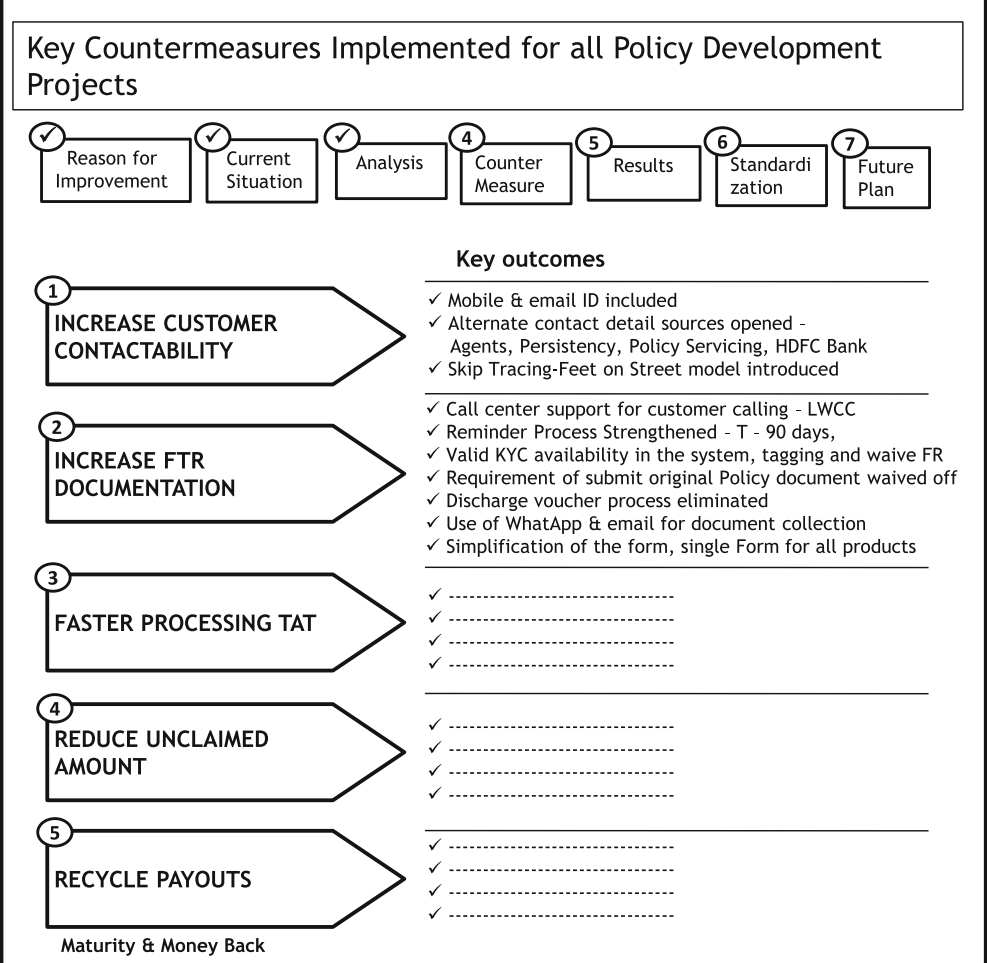

Fig. 9 Synopsis of countermeasures for all PD projects

Table 1 Result summary for PD 1, i.e. customer payouts

\begin{tabular}{|c|c|c|c|c|c|c|c|c|c|}
\hline Number & Project name & $\begin{array}{l}\text { Baseline, } \\
\text { Sept. } 14\end{array}$ & Goal & $\begin{array}{l}\text { Start } \\
\text { date }\end{array}$ & $\begin{array}{l}\text { As of Aug. } \\
15\end{array}$ & $\begin{array}{l}\text { As of Jan. } \\
16\end{array}$ & $\begin{array}{l}\text { As of Mar. } \\
16\end{array}$ & Status & $\begin{array}{l}\text { Project } \\
\text { leader }\end{array}$ \\
\hline 1.1.1 & $\begin{array}{l}\text { Increase customer } \\
\text { contractibility } \\
\text { (Maturity and } \\
\text { Money back) }\end{array}$ & $38 \%$ & $90 \%$ & $\begin{array}{l}\text { Oct. } \\
14\end{array}$ & $\begin{array}{l}\text { MAT-90\% } \\
\text { MBK-90\% }\end{array}$ & $\begin{array}{l}\text { MAT-96\% } \\
\text { MBK-100\% }\end{array}$ & $\begin{array}{l}\text { MAT-96\% } \\
\text { MBK-100\% }\end{array}$ & & Mr. A \\
\hline 1.1.2 & $\begin{array}{l}\text { Make the } \\
\text { customer act } \\
\text { faster and submit } \\
\text { documents first } \\
\text { time right }\end{array}$ & $\begin{array}{l}\text { MAT- } \\
46 \% \\
\text { MBK- } \\
43 \%\end{array}$ & $95 \%$ & $\begin{array}{l}\text { Oct. } \\
14\end{array}$ & $\begin{array}{l}\text { MAT-61\% } \\
\text { MBK-75\% }\end{array}$ & $\begin{array}{l}\text { MAT-68\% } \\
\text { MBK-91\% }\end{array}$ & $\begin{array}{l}\text { MAT-71\% } \\
\text { MBK-100\% }\end{array}$ & & Mr. B \\
\hline 1.1.3 & $\begin{array}{l}\text { Process payouts } \\
\text { on time }(T+1)\end{array}$ & $\begin{array}{l}\text { MAT- } \\
21 \% \\
\text { MBK- } \\
69 \%\end{array}$ & $\begin{array}{l}\text { MAT- } \\
98 \% \\
\text { MBK- } \\
98 \%\end{array}$ & $\begin{array}{l}\text { Oct. } \\
14\end{array}$ & $\begin{array}{l}\text { MAT—99\% } \\
\text { MBK—99\% }\end{array}$ & $\begin{array}{l}\text { MAT—99\% } \\
\text { MBK—99\% }\end{array}$ & $\begin{array}{l}\text { MAT—99\% } \\
\text { MBK—99\% }\end{array}$ & & Mr. C \\
\hline 1.1.4 & $\begin{array}{l}\text { Reduce } \\
\text { unclaimed } \\
\text { amount }\end{array}$ & $\mathrm{Rs} \times \mathrm{Crs}^{\mathrm{a}}$ & $\begin{array}{l}\text { Rs } \\
0.7 \times \\
\text { Crs }^{\mathrm{a}}\end{array}$ & $\begin{array}{l}\text { Jan. } \\
15\end{array}$ & $\begin{array}{l}\text { Rs } 0.7 \times \\
\mathrm{Crs}^{\mathrm{a}}\end{array}$ & $\begin{array}{l}\text { Rs } 0.7 \times \\
\mathrm{Crs}^{\mathrm{a}}\end{array}$ & $\begin{array}{l}\text { Rs } 0.3 \times \\
\mathrm{Crs}^{\mathrm{a}}\end{array}$ & & Mr. D \\
\hline 1.1.5 & $\begin{array}{l}\text { Increase revenue } \\
\text { recycle }\end{array}$ & $0.50 \%$ & $2 \%$ & $\begin{array}{l}\text { Oct. } \\
14\end{array}$ & $1.2 \%$ & $\begin{array}{l}1 \% \\
(\mathrm{NOP}-2 \%)\end{array}$ & $\begin{array}{l}1 \% \\
(\mathrm{NOP}-2 \%)\end{array}$ & & Ms. E \\
\hline 1.1.6 & $\begin{array}{l}\text { Improve CSAT } \\
\text { score }\end{array}$ & $\begin{array}{l}\text { CSAT m } \\
\text { of partn }\end{array}$ & suren & t co & ducted by $3 r$ & d party—cur & ntly in the $p$ & & change \\
\hline
\end{tabular}

Significant improvement across all metrics-set new level of performance within organization processes and for competition. For Maturity Customers, 'act faster' required deep digging as the performance is significantly different from Money Back Customers

${ }^{\mathrm{a} C o n f i d e n t i a l}$ 
With implementation of countermeasures across all PD projects (Table 1), progressively, the results started trending towards the goal set by the team.

In a span of 6 months, the results surprised the organisation as the metrics were at a new level of performance. The quantum of improvement spoke for itself (baseline vs Jan. $16 \mathrm{im}$ proved level) as per Fig. 10.

\section{Discussion and Evaluation}

\section{Sustenance plan}

The actions and results needed to be sustained over time, and this was managed in a structured manner using a sustenance plan/checklist. It was part of the final sign-off process (Table 2).

Apart from the sustained results that were achieved, the biggest gain has been the organisation's enhanced capability and pulls with respect to:

- Developing a critical mass within the organisation which can now be leveraged for larger opportunities, generating the confidence to repeat similar structured approaches to address more policy items

- A larger appreciation for the 'structured way' of problem solving has been engrained in the functions, thereby converting 'reluctant participants' into 'ambassadors' of the approach

Similar to the payout process, the team worked step by step on the second Policy Deployment on 'Service Recovery' theme. As evident in Fig. 2, the organisation was facing

\section{Steps to Sustain Benefits}

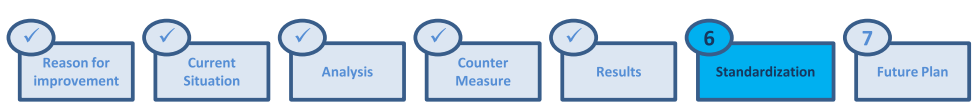

\begin{tabular}{|l|l|}
\hline $\begin{array}{l}\text { Project Sustenance Checklist } \\
\begin{array}{l}\checkmark \text { Process performance metric clearly defined \& ownership } \\
\text { established }\end{array}\end{array}$ & BPM ARIS/ Functional Tracker \\
\hline$\checkmark$ Change Communicated to relevant stakeholders & Project closure confirmation \\
\hline$\checkmark$ Training imparted for the new stakeholders & Internal Training to Team \\
\hline$\checkmark$ Cross-functional interfaces defined through clear SLA's & Branch Ops quality dashboard \\
\hline$\checkmark$ KPI revisited \& aligned & Increase in TAT \\
\hline$\checkmark$ Process document updated & BPM ARIS \\
\hline$\checkmark$ Control report or dashboard or MIS created & Control report and functional tracker \\
\hline$\checkmark$ QNI tracked, signed \& linked with budgets \& revised targets & Not Applicable \\
\hline$\checkmark$ Audit checklist enhanced \& changes integrated with Process & Assessment of Integrated Reality and Risk (AIRr) \\
\hline Control \& Assessment & Checklist \& Functional Tracker \\
\hline$\checkmark$ Mistake Proofing ensured & Not Applicable \\
\hline$\checkmark$ Visual control, Practices \& standards created & Annuity \& Customer Initiated Payouts \\
\hline$\checkmark$ Scope for Replication & Detailed as per action \# 2 for Customer Initiated Payouts \\
\hline$\checkmark$ Replication Plan (Owner, deliverables \& Timeline) &
\end{tabular}

Monthly HoD review of dashboard \& Executive Committee review in MBR

Fig. 10 Project sustenance checklist 
Table 2 Result summary for PD 2, i.e. Service Recovery

\begin{tabular}{|c|c|c|c|c|c|c|c|c|}
\hline $\begin{array}{l}\text { Project } \\
\text { no. }\end{array}$ & Project name & Baseline & Goal & Improve & $\begin{array}{l}\text { Start } \\
\text { date }\end{array}$ & Status & $\begin{array}{l}\text { Project } \\
\text { leader }\end{array}$ & Highlights \\
\hline 2.1 & $\begin{array}{l}\text { Correct clarification of } \\
\text { complaints }\end{array}$ & 375 & 0 & 0 & $\begin{array}{l}\text { Aug. } \\
14\end{array}$ & & Mr. AO & $\begin{array}{l}\text { - Legal/Ombudsman } \\
\text { tagging in } \mathrm{Cl} \\
\text { - Arresting incorrect case } \\
\text { start }\end{array}$ \\
\hline 2.2 & $\begin{array}{l}\text { Reduction in Top } 7 \\
\text { servicing complaints }\end{array}$ & $\begin{array}{l}300 / \\
50 \%\end{array}$ & $\begin{array}{l}90 / \\
30 \%\end{array}$ & $\begin{array}{l}103 / \\
39 * \%\end{array}$ & $\begin{array}{l}\text { Apr. } \\
14\end{array}$ & & $\mathrm{Mr} . \mathrm{AO}$ & $\begin{array}{l}\text { - Non-IGMS cases } \\
\text { contribution has gone } \\
\text { down considerably }\end{array}$ \\
\hline 2.3 & $\begin{array}{l}\text { Reduction in Top } 5 \\
\text { mis-sale complaints }\end{array}$ & 2067 & 620 & 378 & $\begin{array}{l}\text { Sep. } \\
14\end{array}$ & & $\mathrm{Mr} . \mathrm{AO}$ & $\begin{array}{l}\text { - POS implementation } \\
\text { - PCVC script strengthened } \\
\text { for }\end{array}$ \\
\hline 2.4 & $\begin{array}{l}\text { Complaints from top } \\
\text { mis-sale contributing } \\
\text { channel }\end{array}$ & $\begin{array}{l}1083 / \\
39 \%\end{array}$ & $30 \%$ & $\begin{array}{l}233 / \\
49 \%\end{array}$ & $\begin{array}{l}\text { Feb. } \\
15\end{array}$ & & Mr. AO & $\begin{array}{l}\text { - Process premium capped } \\
\text { at IL } \\
\text { - Policy cannot be sold to } \\
\text { life assured }=60 \text { years }\end{array}$ \\
\hline 2.5 & $\begin{array}{l}\text { Theme-based } \\
\text { complaints }\end{array}$ & 660 & 100 & 100 & $\begin{array}{l}\text { Feb. } \\
15\end{array}$ & & Ms. AK & $\begin{array}{l}\text { - Name change process } \\
\text { - Free-look process } \\
\text { alignment }\end{array}$ \\
\hline 2.6 & $\begin{array}{l}\text { Reduction in repeat } \\
\text { complaints }\end{array}$ & $23 \%$ & $15 \%$ & $15 \%$ & $\begin{array}{l}\text { Mar. } \\
15\end{array}$ & & Ms. AK & •Improving FTR \\
\hline 2.7 & $\begin{array}{l}\text { Faster complaints } \\
\text { resolution }\end{array}$ & $23 \%$ & $70 \%$ & $57 \%$ & $\begin{array}{l}\text { Jun. } \\
14\end{array}$ & & Ms. AK & $\begin{array}{l}\text { - Process redesign for non- } \\
\text { bank MS complaints } \\
\text { - SLA's redefined }\end{array}$ \\
\hline 2.8 & Capability building & $68 \%$ & $95 \%$ & $90 \%$ & $\begin{array}{l}\text { Dec. } \\
15\end{array}$ & & Ms. AK & $\begin{array}{l}\text { - SDA parameters made } \\
\text { more relevant to Service } \\
\text { Recovery } \\
\text { - Oct. } 15 \text { SDA score was } \\
94 \%\end{array}$ \\
\hline
\end{tabular}

a real issue, and Table 2 shows the real results of break through nature on reduction in complaints number and response time.

\section{Future plan}

Further, a 2-day workshop was conducted by TQMI on the approach followed and to reflect on 'what went well' and 'what could be improved' in this journey.

Based on the progress on these two PDs, the next set of processes for the PD journey was identified viz. Claims, Medical \& Sales Leakage. The cross-functional team members of the new PDs underwent an inspiration workshop which showcased how the PD1-2 team worked and delivered results, and understood the process of QI Story creation, imbibing the difference in Policy Deployment and Daily Management vs Business As Usual (BAU) way of functioning. The next steps have been identified as:

- Horizontal deployment to other policy items in this financial year

- Further, explore replication opportunities of the solutions identified in the PD projects

- Training a pool of 50+ new members to spread the message and applications

- Diagnosis by Quality Guru Dr. N Kano and TQMI team to have a fresh perspective and new valuable guidance and to make mid-course corrections, as needed

- Drawing a long-term TQM promotion plan based on the journey so far

- Strengthen Daily Management to bring stability in all processes, particularly customer facing processes. 
Table 3 Challenges faced during the projects and our response

\begin{tabular}{ll}
\hline Challenges & How we responded to it? \\
\hline $\begin{array}{l}\text { Feeling that such approach is not } \\
\text { applicable to Service Industry }\end{array}$ & $\begin{array}{l}\text { Showed case studies; customized training and simplified approach. } \\
\text { Expected benefits linked to financial saving }\end{array}$ \\
$\begin{array}{l}\text { Perception that it could be 'Flavor of } \\
\text { the month' }\end{array}$ & $\begin{array}{l}\text { Demo of } 2 \text { PD items have helped. Showcase of success stories by } \\
\text { team members in new areas. Standardized the approach for all to } \\
\text { follow }\end{array}$ \\
Action focus on Symptom & $\begin{array}{l}\text { Training focuses on root cause analysis and its importance. Success of } \\
\text { pilot projects will help further. Standardization of approach helped }\end{array}$ \\
Involvement of Team & $\begin{array}{l}\text { MD/EC reviews; repeat messages from EC on use of structured } \\
\text { process; Governance structure Blitz format brings team urgency and } \\
\text { focus on the project }\end{array}$ \\
Progress delayed against plan & $\begin{array}{l}\text { EC reviews; Message of discipline; message on loss to the company } \\
\text { due to delays } \\
\text { Sustenance of results }\end{array}$ \\
Standardized process; integration with ARIS BPMS; MIS and Audit on \\
process at scheduled frequency
\end{tabular}

\section{Challenges faced and learning}

The journey has been exciting for HDFC Life, and the team had its share of challenges. Some of the critical ones are listed in Table 2 for knowledge sharing with other companies, particularly in service sector.

\section{Conclusions}

We have successfully demonstrated the integration between Policy Deployment and Daily Management to solve the 'real problem' of an insurance organisation. Challenges faced and learning from the exercise helped refine the approach, making it relevant to the industry and the workplace (Table 3). The organisation now perceives a high value in using this approach and replicating the improvement stories in the other business critical areas viz. Claim, Medical and Underwriting.

Although process and approach may look similar, some simplification and customization would further help other service industries.

\section{Additional file}

Additional file 1: Annexure (survey questionnaire). (PDF $15 \mathrm{~kb}$ )

\section{Abbreviations}

BAU: Business as usual; BPMS: Business Process Management System; BSC: Balanced Scorecard; EC: Executive Committee; IMC RBNQA: Indian Merchant Chambers: Ramakrishna Bajaj National Quality Award; ISQ: Indian Society for Quality; KRA/KPI: Key result area/key performance indicator; MD \& CEO: Managing Director and Chief Executive Officer; NIQR: National Institute of Quality \& Reliability; PDCA: Plan-do-check-act; PM/PD: Policy Management/Policy Deployment; QI Story: Quality Improvement Story; RCA: Root cause analysis; SDCA: Standardise-do-check-act; TEl: Total Employee Involvement; TPM: Total Productive Maintenance; TPS: Toyota Production System; TQM: Total Quality Management; TWE: Total Waste Elimination; WCO: World-class organisation

\section{Acknowledgements}

We acknowledge with gratitude the guidance and support provided by the following persons:

1. Mr. Janak Mehta, Chairman, International Academy of Quality and Chairman, and Managing Director, TQM International Pvt. Ltd., New Delhi, India

2. Mr. N Ramanathan, Academician, International Academy of Quality, and TQM Consultant in Bangalore, India 3. Mr. Rajendra Ghag, Director-HR and Quality, HDFC Life Insurance Company Limited, Mumbai, India Support was in the form of review of research work and application of proposed model

\section{Funding}

The paper is based on individual efforts of the authors, and no finding from any external source has been used for the research. The authors have put in voluntary time to get the research complete, and the company HDFC Life Insurance Co. Ltd. allowed us to apply the proposed model. 
Authors' contributions

The research done, model developed and application were joint efforts of both authors, and it will be difficult to segregate individual authors' contribution. Both authors read and approved the final manuscript.

\section{Authors' information}

Anil Sachdev

Age: 55 years

- Qualifications: Graduate in Mechanical Engineering and Masters in Industrial Engineering; Master Black Belt and Certified Trainer for Six Sigma, Lean and DFSS from Motorola University.

- Current job: President, TQM International Private Limited, New Delhi, India; Consultant for Lean, Lean Six Sigma, DFSS and Deming Prize; have facilitated more than 500 Quality Improvement projects in various industry sectors; and have consulted about 10 Deming Prize companies in India.

- Voluntary work: Associate Member, International Academy for Quality (IAQ); Honorary Secretary, Indian Society for Quality (ISQ); and Trainer for Lean Management Institute of India, Part of Lean Global Network promoted by John Shook and Jim Womack

Jitendra Agrawa

Age: 48 years

- Qualifications: Graduate in Production Engineering and Masters in Reliability Engineering; Executive MBA.

- Current job: Senior Vice President, Business and Service Excellence, HDFC Life Insurance Company Limited, Mumbai, India; facilitates in Innovative Quality practices including Larger Scale Interactive Process (LSIP) to create significant financial impact and a strong culture of continuous improvement, embracing Robotics Process Automation, diagnosing process through Business Process Engineering and leading business critical complex Cross Functional Projects.

- Voluntary work: Associate Member, International Academy for Quality. Life Member of Indian Society for Quality; Member, Quality Council of India; and Member, Lean Management Institute of India.

\section{Competing interests}

The authors declare that they have no competing interests.

\section{Publisher's Note}

Springer Nature remains neutral with regard to jurisdictional claims in published maps and institutional affiliations.

Received: 14 February 2017 Accepted: 11 October 2017

Published online: 02 November 2017

\section{References}

1. Union of Japanese Scientists and Engineers, "Deming Prize Guide: Overseas" (2008)

2. Kume H Management by quality, 2nd edn. Quality and Productivity Publishing Pvt. Ltd., India

3. Kaplan, R \& Norton, D, The balanced scorecard - measures that drive performance: Harvard business review January-February 1992

4. Hosotani K (1992) Japanese quality concepts. Quality Resources

5. Kume H (2006) Statistical methods for quality improvement. Productivity Press India

6. Ando Y, Kumar P (2011) Daily management the TQM way: the key to success in Tata Steel. Productivity \& Quality Publishing Pvt. Ltd

7. Japanese Industrial Standard, JIS-Q-9026, Performance improvement of management systems_-guidelines for daily management (2016)

8. Kano N (1996) Guide to TQM in service industries. Asian Productivity Organisation

9. Sachdev A (2014) Challenges and approach in implementation of TQM in service organisations, paper presented in International Conference on Quality, Tokyo

10. Agrawal, Jitendra, Establishing quality cost system: a gold mine for service organisation, paper published in the Journal of Insurance Institute of India (III), Oct-Dec (2013), page 99-106 